
for substantive argument and deliberation

\title{
"Taking Issues"
}

Correspondence concerning this column should be addressed to Karen Antell, Head of Reference \& Outreach Services, and Molly Strothmann, Social \& Behavioral Sciences Librarian, University of Oklahoma Libraries, 401 W. Brooks St., Norman, OK 73019; e-mail: kantell@ou.edu and mstrothmann@ou.edu. reference and user services. Contributions to this column will consider topics that have generated professional controversies and debate them from two (or more) opposing viewpoints. We hope to use this column to create an opportunity for active discussion, a space in which librarians with different opinions and perspectives on our professional issues can engage with one another directly.

We chose the name "Taking Issues" for two reasons. First, that's the intellectual charge we're asking our contributors to embrace: Take up an issue that matters to the practice of librarianship and enter a conversation about it. Second, the name evokes the spirit of lively, informed debate that we want to encourage. Contributors will use this column to "take issue" with their colleagues' ideas and arguments, to explain their differences of opinion, and to defend their positions. As an example of the sort of debate we envision in this column, we use this first installment to discuss reducing the size of libraries' print collections, weighing the physical space gained against the content lost.

We seek contributors to co-author columns that debate both sides of an issue relevant to reference and user services. If you and a colleague have an ongoing disagreement on such a topic, please consider outlining your viewpoints and the reasons for your disagreement in "Taking Issues." Email column proposals to the editors at kantell@ou.edu and mstrothmann@ou.edu.

\section{COLUMN GUIDELINES}

- The scope of this column is "issues worth debating in reference and user services." We've intentionally made the range of suitable topics as broad as possible, and we encourage contributors to discuss issues that affect all aspects of our work in all sizes and types of libraries.

- Topics should have some current relevance to the RUSQ readership. Relevance, however, needn't imply newness. You can use this space to weigh the pros and cons of the latest innovation in library services or technologies, certainly. But you can also use it to explore the abiding debates of our profession. We believe that many classic topics deserve ongoing reflection, and we hope to provide a space where they can be discussed with fresh perspectives. 
- We envision that most columns will be co-authored, with each author advancing one side of the discussion. Our preference will be for authentic debate between two colleagues who hold different views, rather than columns that merely delineate the available positions. In other words, it's not necessary to put aside your own opinions-in fact, please don't. (Incidentally, we genuinely do disagree with each other about the print retention issue that we debate below.) Each side should be signed.

- If necessary, we will attempt to match contributors with appropriate writing partners. If you are committed to a position that you want to defend zealously and would enjoy the opportunity for an animated debate, but you haven't been able to identify any colleagues who hold the opposing viewpoint, contact us with your idea. We will try to find someone to gainsay you.

- While "Taking Issues" will usually feature two contributors arguing opposing viewpoints, we will entertain contributions by single authors so long as they are in keeping with the column's spirit of debate. If you've argued-passionately-with yourself about an important topic, you may use this column to convey your thought process to your fellow librarians. It can be wonderfully instructive to listen to an informed colleague grapple with an idea she has pondered deeply, even if she hasn't yet reached a staunch conviction about it.

- By the same token, not every issue has just two legitimate sides. Some have three. Some have fifty. If you have an idea for a column that is better suited to a conversation representing multiple opinions than to a simple pointcounterpoint, tell us about it. (You probably won't have space to explore all fifty, unfortunately.)

- We encourage challenges to the conventional wisdom. If you find yourself thinking, "The entire profession of librarianship seems absolutely convinced that $A$ is true, but I'm certain it's really $Z$ and I have evidence to prove it," then you have an idea for a "Taking Issues" column. Pinpointing exactly what constitutes "the conventional wisdom" is hardly an exact science, of course. By challenging what appears to be the consensus, we may sometimes discover that dogma is not as universally embraced as it seemed.

- There is no need to attempt to reach a resolution or a synthesis, nor to decide whose position is the right one. If you and your co-author utterly fail to persuade one another of anything, say as much. Most debates worth having can't be dispatched in three thousand words, and we do not propose to attempt to pick a winner.

- The format is flexible. We structured this introductory column as a dialogue because that approach allows one author to respond directly to the other's assertions. You may prefer a traditional "point-counterpoint" style-two discrete, stand-alone sections that lay out each argument. Let the nature of the debate dictate the arrangement of the column.

- Columns should be approximately 3,000 words long, no more than 3,500. Authors may allot those 3,000 words however they chose- it is not always necessary that each side receive equal space. If you believe that one position has been exhaustively advanced in the library literature and rarely contradicted, you may find it more appropriate to sketch the dominant view quite briefly before devoting most of your space to attempting to dismantle it.

- If you would like to contact us about your proposed topic before writing a column, we would be glad to hear from you and give you feedback about whether your topic is suitable for the column. But we also welcome unsolicited submissions.

And now, on to this column's first topic of debate.

\section{IS IT TIME TO GET RID OF THE BOOKS?}

Every April, American Libraries highlights new and newly renovated library buildings, with page after glorious page showing drool-worthy images of beautiful and functional new spaces. Anyone who has picked up a copy of the April issue in recent years will have noticed that, in library renovations, user spaces seem to be taking precedence over spaces for library books. Indeed, many new and renovated libraries have made the difficult decision to reduce their collection sizes dramatically to create spaces for library users. Gathering rooms, information commons areas, and coffee shops are among the most common.

Some library patrons adore and appreciate the new user spaces, but for other patrons, the refurbished spaces prompt the panicked question: "What happened to the books?" Although our library (at the University of Oklahoma) has not undertaken a major renovation since 1982, we and our colleagues have informally discussed the possibilities of our space, which (as at many libraries) seems to be dwindling as our collections grow each year, with no foreseeable possibility of expansion.

Of course, any group of three or 30 librarians will have three or 30 different opinions about the best possible allocation of their library's space. Here are two of them.

\section{Karen:}

I've never said we should get rid of all the books, or even most of the books. But I've learned, as have many librarians, that advocating for even a modestly smaller collection can prompt reactions of disbelief and shock among our patrons and the general public. The typical reaction runs along the lines of "I thought librarians loved books! How can they bear to discard them?" When the University of New South Wales in Australia reduced the size of its collection by 50 percent in 2011, one faculty member lamented "there's something profoundly wrong, and symbolically wrong, about a university destroying books. Universities are in the business of passing on knowledge, and books - no matter how the use of books is shrinking-still remain a very important symbol of knowledge." 


\section{TAKING ISSUES}

In my opinion, this common and impassioned plea argues precisely for, not against, reducing the size of book collections. To be certain, books are a symbol of knowledge. But shelf space is not unlimited, and books are merely one of many vessels that contain knowledge. In these days of online information and decreasing circulation figures, librarians can be wholly committed to preserving and transmitting knowledge while simultaneously advocating for much smaller book collections. Holding on to books merely for their symbolic or sentimental value does nothing to promote knowledge and, in fact, is often counterproductive. After all, maintaining a collection of books is not cost-free. Books that are rarely or never used are not "earning" their place on the shelves and should be discarded in favor of a different use of the space they take up-a use that promotes the values of the particular library and its community. More specifically: The existence of knowledge requires not just books (and other information packages) but also people; and space that enables people to receive, discuss, debate, share, and transmit knowledge is a productive use of space for any library.

\section{Molly:}

It's ironic that the first consideration you bring up is the symbolism and sentimentality attached to books-books as emblems of learning instead of as information packages-because I've found that if anything, I've actually become a lot less sentimental about books since becoming a librarian. I used to treat cheap, tattered paperbacks as inherently precious, carefully moving them from apartment to apartment, finding room for them that I didn't really have to spare, never discarding anything, no matter the condition-not just special favorites: every book I owned. Now, thanks to professional experience, I suffer no pangs of loss at all in telling myself of a ruined or worn-out volume, "There are a lot of copies of Emma in the world; this particular one is ready for the recycling bin."

So I'm happy to begin with that concession: that which is easily replaceable shouldn't be treated with artificial attachment, and the aesthetic and atmospheric value of endless stacks of books isn't, by itself, enough to justify their retention.

But knowledge isn't fungible: one cannot "swap out" that dusty 1967 physics textbook for the latest online database of literary criticism and assert that, since the database contains more words than the physics book, the exchange marks a net increase in our commitment to preserving and promulgating knowledge. Even if that's mathematically accurate, we're still talking about eliminating specific, unique units of knowledge without replacing them. When we remove a book from our shelves, we remove that particular quantum of knowledge from our holdings. Even if we acquire other vessels of different information at the same time, there's a unique loss of knowledge and ideas to each such elimination.

\section{Karen:}

You're right, of course. Reducing the size of the book collection in our library (without replacing the content electronically) entails a unique loss of knowledge from our library. In fact, I would go so far as to say that, in many cases, replacing print materials with "identical" electronic content constitutes a loss. I am reminded of a doctoral student I met recently who is studying magazine advertisements geared toward African American women in the 1920s and 1930s. Even when such periodicals are digitized, it is often difficult or impossible to browse non-indexed material such as advertisements, so discarding the print in favor of electronic access really does result in a loss of information. This student's provocative dissertation might be impossible to complete if she does not have access to long print runs of popular magazines.

But losing particular information packages from our library does not mean that the knowledge in question is lost from the face of the Earth. At the University of New South Wales, librarians checked each book to make sure they did not discard the last remaining copy in Australian libraries, and this kind of vigilance is of utmost importance when any library undertakes a major reduction in collection size. This is true not just for large research libraries but for all libraries: Any library of any size may hold rare, unique, or local materials that are not found in many other collections.

Even if we are careful to retain rare, unique, and local materials during a major reduction in collection size, though, how can we justify the inevitable "unique loss of knowledge" from our library? I assert that such a loss is more than balanced by the concomitant gain in library space. But space gains are commonly dismissed by patrons and the general public. One professor at the University of New South Wales had a typical reaction to his library's space reallocation: "They've turned the library into a kind of Starbucks."

The implication is that such as exchange is not worthwhile: Losing books and gaining a coffee shop is no gain at all. And perhaps this is true-in some libraries. Clearly, some uses of reallocated space are better than others. But just as each library's collection reflects its values and its community's needs, so too does each library's use of space. A coffee shop might not be the most sensible use of space in every library, but I maintain that in some libraries, gaining a coffee shop-or a smart classroom, or an information commons, or a childcare center-could more than offset the loss of a great many books.

\section{Molly:}

True, removing information from a single library doesn't obliterate it. And I agree that under some circumstances, increased cooperation with our holdings can reduce the need for duplication at multiple academic libraries-a principle that applies to new purchases as well as to decisions about item retention.

However, the loss of content from an individual collection represents, at the least, a blow to patron convenience. If we are still committed to "saving the time of the reader," then imposing barriers to access is contrary to our values. The doctoral student you mentioned above probably still could have figured out a way to complete her research if we had 
eliminated the periodicals she needed from our stacks-after all, those advertisements still existed. She could perhaps have browsed the unindexed content online, or traveled to another library, or attempted interlibrary loan requests (and hoped that we could find a lender with generous policies about bound periodicals). All those alternatives would have been more trouble for her than the current option: using the items we have on our shelves. We would have served her poorly by eliminating that content.

In addition, I'm unconvinced that guarding against eliminating the very last copy of particular title is a sufficient standard. I'm reminded of the logic behind the LOCKSS Program for preservation of libraries' digital content-Lots of Copies Keep Stuff Safe. Operating from the premise that "no single library can achieve robust long-term preservation alone," LOCKSS protects permanent access to digital content in part by enabling libraries to maintain local copies. ${ }^{2}$ Shouldn't we, as the community of research libraries, be as conscientious with our print collections?

Just as you aren't arguing that we should summarily get rid of all the books, I'm not claiming that we have an unbreakable commitment to keep every volume that we own forever. As local needs change, librarians do sometimes find that some materials simply aren't as important as they used to be. Research libraries have an obligation to serve our current users and to support local needs, and our collections, as you say, should reflect that.

But we also have a duty, in my opinion every bit as solemn, to future users. As such, we must balance our support of current needs with our obligation to preserve access to the scholarly record for future generations of researchers. We can't always predict what will be important for research decades from now, but it's not necessarily just the materials that are currently in demand. After all, who knew, eighty years ago, that those magazine advertisements would someday become dissertation fodder?

When we reduce the size of our collections, I believe that we often overvalue current usage rates as a measure of the worth of the books we hold. If we use current circulation statistics alone to decide what should be kept-saying, essentially, that only those books that have been read in the past year or two have "earned" their place on our shelves-then we may well create bias in our contribution to the scholarly record. What we will have provided for scholars decades or even centuries hence won't be our collection, but the fraction of our collection that happened to be in use when we decided to reduce its size. No, keeping low-use books isn't without cost, but I believe that bearing that cost is part of our responsibility to future scholarship.

Similarly, I believe that we should consider what obligation we have to researchers beyond our walls. In my opinion, although our primary concern should be the members of our own academic communities, research libraries should also make collection decisions that respect the needs of the broader world of scholarship. You didn't use an argument that I was expecting to see crop up in this discussion, but if you'll forgive me I'll address it anyway, since it's a recurrent point in this conversation: If we reduce our local holdings, we can depend more on interlibrary loan. It's certainly appealing: To increase sharing of our holdings among institutions, so that scholars have quick and convenient access to the holdings of institutions beyond their own, is marvelous. But at the risk of being obnoxious in pointing out the obvious, somebody has to be the lender. If we eliminate lower use titles from our collections, I worry that we shirk our obligation to be reciprocal partners when other libraries' patrons need us. For instance, I recently stumbled across a thirty-year-old psychology book in our stacks, written in Finnish. Unsurprisingly, it's never circulated. But it has gone out on interlibrary loan twice, and although ours isn't the last copy, it's not exactly widely held. I am never going to weed that book, despite the fact that it's unlikely it will ever serve local needs, because I believe in ensuring its availability for outside researchers. Current, local needs are important, of course-but so are future and national (or international) needs. Preservation decisions must balance our responsibilities to both.

I've been concentrating on the inevitable loss entailed by the elimination of books; I'll turn now to your argument about the gain of repurposing space. My knee-jerk reaction, I admit, is to join your chorus of patrons and the general public in dismissing them outright, but I'll try to be more thoughtful. And that takes us to the fundamental question-what are research libraries for? That's a much larger question than the scope of this column permits, of course, but I'll give my own three-word answer: scholarship and learning. Therefore, I believe that as we decide how to use our physical space, the fundamental question should be: Does this use of space support scholarship and learning?

Not every librarian will agree about the conclusions, and not every library should allocate its space in precisely the same way, but I believe that's how the decision is best framed. So ... about that coffee shop? I suppose having one in the library can support our scholarly mission, indirectly, in that it gives researchers and students space to gather and share ideas. What about using the space to preserve the best collection of books we can; does that serve scholarship and learning? In my opinion, the answer is absolutely yes-even if some of those books are rarely read and are largely being held in trust for the future. That's why I aver that the books need to stay.

\section{Karen:}

You claim, correctly, that removing books throws up barriers in the way of our patrons, who will be inconvenienced by having to travel to distant libraries, request interlibrary loan items that might be impossible to procure, or browse inadequately indexed online or microform versions of the discarded print materials. This is a legitimate concern and should not be dismissed lightly: "save the time of the reader" is still a fundamental value of librarianship.

But simply asserting that we have a duty to bear the cost of maintaining large numbers of unused books in our 


\section{TAKING ISSUES}

collections amounts to an unfunded mandate. In an ideal world, of course, we would build facilities as large as necessary to keep up with collection growth while also providing adequate space for user activities that reflect the particular library's mission and values. In this world, though, library space is limited, and often, we must decide between space for books and space for users.

At the University of Oklahoma's engineering branch library, where I worked from 2003 to 2006, we faced a critical shortage of shelf space. If I had chosen to keep every book, we would have had to eliminate most of our already minimal patron space. Instead, I transferred some books to the main library (in effect, creating a space problem for someone else) but also weeded aggressively. This was not an ideal solution, but nonetheless I am proud of my decision. The user spaces I "saved" are used heavily every hour that the library is open and are the site of a thriving undergraduate tutoring program. I feel confident in asserting that this space is a greater contribution to student learning than the many 1980s-vintage WordPerfect 4.1 manuals I discarded.

At libraries with acute space shortages, we are forced to choose between spaces for books and spaces for users. Keeping every print volume by default is, in fact, a choice to disregard the knowledge receiver-the library user-in favor of the knowledge vessel.

\section{References}

1. Yuko Narushima, "Books Get the Shove as University Students Prefer to Do Research Online," Sydney Morning Herald (Mar. 8, 2011): 1 .

2. "LOCKSS: Lots of Copies Keep Stuff Safe," accessed May 8, 2012, www.lockss.org/about/principles. 